Revista de Estudios Andaluces, n. ${ }^{\circ} 13$ (1989), pp. 21-44

https://doi.org/10.12795/rea.1989.i13.02

\title{
LOS PRIMEROS ESTUDIOS SOBRE LA CULTURA POPULAR EN ANDALUCIA
}

\author{
Encarnación AGUILAR CRIADO*
}

\section{INTRODUCCION}

Durante la segunda parte del siglo XIX se va a afianzar una nueva orientación en las ciencias, que desde el mundo de la elucubración habían recorrido el camino necesario para sentarse sobre bases experimentales. Los científicos del momento apoyados en la triunfante corriente del positivismo se mostraban orgullosos de unos nuevos métodos de investigación comprobables y deducibles, que harán posible la aparición de campos científicos y de nuevas teorías y escuelas. De todas será el evolucionismo la que marcará con su sello estas décadas, la que con sus innegables demostraciones inaugure el predominio absoluto de las Ciencias Naturales y Biológicas, y junto a ellas unas nuevas Ciencias Sociales, dispuestas a recoger datos con que arrojar ellos luces al estudio del origen y desarrollo del hombre. La aparición de la Antropología en este contexto, era más que explicable.

De cualquier forma este ambiente intelectual no será paralelo en todas las naciones europeas, cuestiones ideológicas y políticas del momento potenciarán o frenarán esta tendencia general. De ahí que, tras el derrocamiento de la decadente monarquía borbónica, y el triunfo de ese sueño político que fue la Revolución del 68, España se suma, con retraso, a un ambiente ya mayoritario en Europa. Los nuevos aires de libertad económica, política-social e ideológica impuestos por la burguesía triunfante harían posible la remodelación necesaria de las anquilosadas estructuras intelectuales y científicas de este país ${ }^{1}$.

Este cambio coyuntural posibilitaría la expansión de las más novedosas teorías filosóficas en boga por Europa. Primero serían los principios de la filoso-

* Departamento de Antropología Social y Sociología. Universidad de Sevilla.

1. De la amplia bibliografía sobre estos momentos políticos destacamos M. Tuñón de Lara: Estudio sobre el XIX español. Siglo XXI, Madrid, 1972. Y J. Fontana: Cambio económico y actitudes politicas en la España del siglo XIX. Ariel, Barcelona, 1983. 
fía Krausista, que dieron al sector progresista de nuestra burguesía e intelectualidad el ideario necesario en el que basar todos los proyectos de reforma, a cuyo calor nacería el interés por profundizar en materias como la historia y la literatura nacional como medio de encontrar las raíces propias. Después, las teorías de Darwin se instalarían entre algunos de nuestros más prestigiosos científicos, que desde entonces comenzarían el duro combate por su defensa y difusión rodeados de un panorama de recelos y ortodoxia católica largamente asentados en el mundo científico ${ }^{2}$.

Representantes muy destacados de estas dos teorías coincidieron por estas fechas en la Universidad de Sevilla, donde las dos corrientes mencionadas habían sentado ya escuela gracias a la labor y al prestigio profesional de dos de sus más importantes catedráticos, seguidores respectivos de las mismas: Federico de Castro, al frente del Departamento de Historia Natural y Metafísica, y D. Antonio Machado y Núnez, en el de Historia Natural.

Federico de Castro, desde su Almería natal había cursado su carrera universitaria en Madrid, circunstancia que lo pondría en contacto con los círculos krausistas de la ciudad creados en torno a Julián Sanz del Río, el maestro indiscutible de tal filosofía y su principal introductor en España. Pronto el joven Castro destacaría como uno de los principales discípulos de Sanz del Río, y con tal bagaje y formación intelectual se incorporará a su cátedra sevillana en 1861, donde a partir de ese momento comenzará a introducir las enseñanzas de su maestro, rodeándose de un amplio círculo de jóvenes alumnos y seguidores, convirtiéndose en unas de las cabezas del movimiento krausista anda$\operatorname{luz}^{3}$.

Antonio Machado y Núñez, por su parte, procedía del campo de la medicina, carrera que cursaría en el prestigioso Colegio de Cirugía de la ciudad de Cádiz. Su curiosidad científica le hará verse pronto atraído por el mundo de las Ciencias Naturales, lo que le llevará a realizar una serie de viajes por Europa, donde bajo la dirección de científicos como Presvost, Dumas y Becquerel, completará sus estudios en Botánica e Historia Natural. Como sucediera con Sanz del Río, el contacto con las principales figuras europeas de su cam-

2. Para un acercamiento a los principios krausistas recomendamos: J. López Morilla: El krausismo en España. F.C.E. México, 1980. Para un análisis de sus figuras y su papel en la sociedad española, ver: D. Gómez Molleda: Los reformadores de la España contemporánea, y E. Terrón: Sociedad e ideología en los orígenes de la España contemporánea. Para el caso andaluz: J.R. García Cué: Aproximación al estudio del krausismo andaluz. Tecnos. Madrid, 1985. Por lo que se refiere al darwinismo y el contexto de su polémica aceptación: T. Glick: Darwin en España. Península. Barcelona, 1982, y D. Nún̆ez: El darwinismo en España. Castalia. Madrid, 1977.

3. Datos biográficos de Federico de Castro pueden encontrarse en J.R. García Cué, o.c. 1985. También en D. Gómez Molleda, o.c. 1966, pp. 288-289. Sus datos académicos están en el Archivo de la Universidad de Sevilla. Legajo 1236, n. $^{\circ} 10$. 
po, lo convirtió en un ferviente seguidor de las más avanzadas corrientes científicas del momento, consagrándolo como una de las personalidades de mayor talla intelectual del momento en nuestro país, muy por encima de la mediocridad generalizada de las aulas universitarias de entonces. En 1846 tomaría posesión de su cátedra sevillana, y allí, desde los tempranos años de 1860 explicaba en profundidad a sus alumnos las teorías darwinistas, convirtiéndose así en uno de los pioneros de su difusión en España ${ }^{4}$.

La Revolución del 68 brindaría a ambos profesores puestos destacados en la política universitaria, lo que les daría, como a tantos otros compañeros, la oportunidad de poner en marcha una nueva política intelectual, científica y pedagógica. Machado y Núñez, cuyo compromiso social le llevaría tener un destacado papel en la política de la ciudad en los días de la Revolución, ocuparía a partir de 1868 el cargo de Rector de la universidad sevillana, al tiempo que su compañero Castro será designado como Decano de la Facultad de Filosofía y Letras. La Universidad Hispalense, se convertía ahora en un foco activo de renovación, punto de encuentro entre el racionalismo armónico krausista, y el positivismo.

El buen hacer de ambos y su estrecha colaboración en todos los órdenes haría de este encuentro más que una anécdota casual, y les llevaría a emprender proyectos y realizaciones muy concretas —creación de cátedras nuevas, ampliación de los cursos de doctorado, impulso a especialidades técnicas, fomento de las enseñanzas prácticas y experimentales de los alumnos, dotación del Gabinete de Químicas y de la Biblioteca de la Facultad de Filosofía-. $\mathrm{Al}$ calor de todo este ambiente se formaría un importante grupo de intelectuales andaluces. La ciudad serviría de lugar de cristalización a una orientación científica nueva, que la convertiría durante mucho tiempo en unos de los focos de mayor prestigio intelectual del país. Es en este contexto específico, y con un marco de referencia anterior más amplio, donde hay que insertar el movimiento de folkloristas andaluces ${ }^{5}$.

Dentro de la misma creciente actividad del grupo y amparados por la reciente promulgada libertad de prensa, Machado y Castro van a fundar una revista científica, que se sumará a las numerosas creadas, por entonces, en nuestro país. Fueron éstos unos años de especiales frutos para una prensa que jugó un importante papel como vehículo cultural al difundir las nuevas ideas, al

4. Sobre A. Machado y Núñez, ver: Archivo Universidad de Sevilla: Legajo $120, \mathrm{n} .^{\circ} 26$, también J.R. Garcia Cué: o.c., 1985, pp. 80-96.

5. Sobre el tema remitimos a la obra de E. Aguilar Criado: Cultura Popular y Folklore en Andalucía (Los orígenes de La Antropología). Sevilla, Diputación Provincial, 1990. El presente artículo está basado en dicho estudio. Consultar tmabién a Isidoro Moreno Navarro «La Antropología en Andalucía. Desarrollo histórico y estado actual de las investigaciones». Etnica, n. ${ }^{\circ}$ 1, Barcelona, 1971, pp. 
polemizar con las distintas tendencias de pensamiento y al dar a conocer a intelectuales y literatos, quienes en su mayoría escribían en algún diario o revista. Estas últimas alcanzaron una calidad igualable a las mejores que por aquéllos momentos se editaban en Europa ${ }^{6}$. Este era el caso de la Revista Mensual de Filosofía, Literatura y Ciencias de Sevilla, cuyo primer número vería la luz a principios de 1869 , y en cuya cabecera figuraba, a modo de declaración de principios, la que iba a ser inequívoca filiación y orientación de la publicación:

«La Redacción a los Lectores:

La libertad de pensamiento, de asociación y de enseñanza, devolviendo a los centros científicos la individualidad que había absorbido el Gobierno, hasta donde esto es posible, mediante reglamentos y disposiciones represivas, exige órganos de inmediata y continua comunicación que, al par que sirvan de mútuo estímulo y ayuda, preparen la verdadera unidad que sólo puede resultar de racionales convicciones. Para cumplir estos fines, en cuanto esté de nuestra parte, hemos fundado esta Revista. Cualquiera que sea el mérito de su trabajo no obedecerá más que a las elevadas aspiraciones de la Ciencia» ${ }^{7}$.

A través de la Revista Mensual es posible reconstruir toda la riqueza intelectual de este período, y por lo que a nuestro tema se refiere, con ella nos situaremos en el contexto preciso que posibilitó el inicio de los primeros estudios sobre la realidad cultural andaluza. Muy pronto, en torno a la figura de los dos fundadores, Machado y Castro, se aglutinó un creciente grupo de profesores, intelectuales y jóvenes estudiantes seguidores de las dos corrientes de pensamiento dirigentes de todo este movimiento. Serán ellos, los que colaborando con sus investigaciones, traducciones de artículos, o dando cabida a trabajos originales de reputados profesionales europeos mantendrán puntualmente informado a los lectores de cuantas actividades y novedades científicas y bibliográficas tuvieran lugar en España o el extranjero, y ésto, en los distintos campos del saber, tal y como se explicitaba en el propio título de la publicación.

6. Unos meses antes de la Revolución del 68 aparecería la prestigiosa Revista de España. El papel de la prensa y otras publicaciones científicas en la España de fines del XIX es estudiado por: M. Tuñón de Lara y otros: Prensa y Sociedad en España. Edicusa. Madrid, 1975. Iris M. Zabalza: «La prensa ante la Revolución de 1868». En Clara E. Lida: La Revolución del 68: Historia, pensamiento, literatura, Las Américas Publishing Company. New York, 1970. Para el caso sevillano es de obligada consulta: M. Chaves: Historia y bibliografia de la Prensa sevillana. Impr. E. Rasco. Sevilla, 1896.

7. Revista Mensual de Filosofía, Literatura y Ciencias de Sevilla. Impr. Gironés y Orduña. Sevilla, $1869,{ }^{\circ} .^{\circ}$, p. 1. 


\section{EL «CATHALOGUS METHODICUS MAMMALIUM»}

Como no podría ser de otro modo, las teorías de Darwin fueron objeto de numerosos artículos, como lo fueron en su conjunto todos los campos científicos que al calor de ellas se desarrollaron, entre ellos habría que citar los casos de la Paleontología, la Arqueología, la Prehistoria y la Antropología. Por su profundidad y por su novedad merece ser destacado de entre todos una serie de trabajos escritos por el propio Machado y Núñez titulados genéricamente «Cathalogus Methodicus Mammalium», donde tal y como se expresaba en tan ostentoso título se pretendía hacer una clasificación de los mamíferos andaluces, comenzando, claro está, por el mismo «hombre andaluz». El trabajo, más allá de la lógica orientación naturalista de su autor constituye el primer acercamiento científico a la realidad cultural andaluza, donde se señalan, junto a las esperables especificidades físicas de sus habitantes, algunos rasgos culturales, y hasta psicológicos, originadas por una trayectoria histórica común, en la que el autor hace incluso algunas muy acertadas incursiones ${ }^{8}$.

Tras una introducción con detallada clasificación, en terminología linneana del hombre andaluz, incluido según su autor en: el «Homo Sapiens», «Varietas Caucásica» y «Forma Baetica», se pasa con detalle a describir algunas de sus peculiaridades físicas en los siguientes términos:

«El andaluz, de cuerpo mediano, estatura de $1 \mathrm{~m} .56 \mathrm{~mm}$. hasta $1 \mathrm{~m} .65$ $\mathrm{mm}$., temperamento sanguineo bilioso, habita en las provincias comprendidas en los antiguos reinos de Granada, Jaén, Córdoba y Sevilla. Su cutis es poco encarnado, moreno, ligeramente pálido; los cabellos largos, finos y sedosos, son por lo general, castaños o negros; la cabeza es mediana; el cuello grueso; la cara oval; la barba poblada; los ojos son rajados y grandes, negros o pardos; las cejas arqueadas; las pestañas largas y sedosas; la nariz recta, algo gruesa en la base y deprimida en la raiz, es muchas veces aguileña; la boca regular, con los labios delgados, o abultados ligeramente; las orejas levantadas, medianas; la barba es poco salilente; los piés y las manos son pequeños» ${ }^{9}$.

En principio la idea de clasificar al andaluz en términos de subraza pudiera parecer exagerado, si no lo ponemos en el explicable contexto de una época obsesionada por clasificaciones y catalogaciones de este tipo, características de unas Ciencias Naturales en plena moda. Machado reconoce este hecho y

\footnotetext{
8. A. Machado y Núñez: «Cathalogus Methodicus Mammalium». Ibidem. pp. 65-74; 105-112; $180-184 ; 193-200 ; 225-230$.

9. Ibidem. p. 65 .
} 
a continuación reafirma sus primeras manifestaciones con argumentaciones de índole más científica:

«Sin embargo, todos reconocen en los diversos pueblos de las provincias andaluzas, semejanzas en la conformidad general de sus naturales, analogías en lo físico, tendencias morales uniformes, parecidas modulaciones en su acento y forma de hablar, propersiones intelectuales semejantes, tendencias y arranques unisonos y otras señales indescriptibles, que nos revelan un pueblo de origen común, modificado por las mismas causas, sujeto a influencias de idéntica naturaleza, y con un sello especial que lo distingue de los otros de la Península Ibérica» ${ }^{10}$.

No podían reflejarse de forma más sintética los rasgos que explican y conforman una especifidad étnica, en este caso la andaluza, considerada, además, no como algo cerrado y uniforme, sino abierto a las diferencias y matices de sus distintas provincias. No menos certeros, aunque de lógica menor extensión son los distintos acercamientos que el autor realiza a los rasgos psíquicos de los andaluces: la mirada penetrante, escudriñadora y altiva, la imaginación y la agudeza. Así como a los de mayor interés para nosotros, los de naturaleza cultural. Lo hace cuando describe algunos de los usos culinarios de los hombres del campo, que por cierto señala como exiguos para soportar las duras jornadas de trabajo, pues: «todo su alimento se reduce a las migas o sopas con aceite y ajo frito en el invierno; con vinagre, aceite y sal en el estio (gaspacho)» ${ }^{11}$.

La dureza de su vida no convierte al andaluz en un hombre sumiso, sino con un característico espíritu independiente, altivo y orgulloso, consecuencia de un enraizado sentido del igualitarismo:

«Nunca faltan a la política, y a las conveniencias sociales, según su clase; pero la dureza de otro hombre a quien creen su igual (y para ellos todos lo son) los exaspera y le arrojarían a la cara el pedazo mismo de pan que tuvieran para alimentarse aquel día, si al cogerlo hubiese de sufrir en su orgullo o en su amor propio» ${ }^{12}$.

Este sentimiento igualitario es la causa de la característica actitud andaluza de burla, convertida en sorna y guasa, en «humor festivo», según denominación del autor, ante cualquier situación que se percibe como superior. Actitud

\footnotetext{
10. Ibidem. p. 66 .

11. Ibidem. p. 69.

12. Ibidem. pp. 71-72.
} 
que obedece a negar, al menos a un nivel simbólico, la propia inferioridad, que es percibida, pero nunca reconocida, y que contradictoriamente tiende a convertir en ridícula la superioridad del contrario:

«...cuando hablan con algún extranjero empiezan por creer que la calidad de tal los hace inferiores a ellos: dignos son de escucharse los diálogos que tienen con estos en los que conservando en apariencia la gravedad, se burlan» ${ }^{13}$.

Recientes planteamientos realizados desde los campos de la Historia y la Antropología han dado una base más sólida a estas características que, adelantándose a su tiempo, señalaba Machado. Hacen tales interpretaciones alusión a la prolongada presencia árabe en Andalucía, lo que provocaría su no plena incorporación al sistema feudal, por entonces vigente en el resto de Europa. La casi inexistencia de relaciones de vasallaje, por la condición de hombres libres que la Corona otorgó como privilegio a los repobladores cristianos de estas tierras, y la temprana implantación de un avanzado sistema de relaciones de producción precapitalista en amplias zonas agrícolas, fueron circunstancias que indudablemente tuvieron que influir en la conformación de las características culturales de este pueblo, fruto de una percepción de la realidad distinta y específica. De todas formas, tendremos que esperar a que futuras investigaciones profundicen y aporten nuevas luces sobre estas cuestiones ${ }^{14}$.

\section{LA SOCIEDAD ANTROPOLOGICA DE SEVILLA}

El número correspondiente a octubre de 1871 de la Revista Mensual se anunciaba la creación de la Sociedad Antropológica de Sevilla. Se trataba de otra más de las iniciativas de este activo grupo de intelectuales sevillanos. Lógicamente la iniciativa estuvo a cargo del seetor evolucionista, y el Discurso Inaugural recaería en la persona de Antonio Machado y Núñez, quien definiría la nueva ciencia en los siguientes términos:

«La Antropología es la ciencia del hombre, es el conocimiento de su ser material, considerado como la síntesis de todos los organismos animados; es la historia de los adelantos que la civilización ha heeho en

13. Ibidem. p. 72 .

14. Véanse al respecto los análisis de A. Domínguez Ortiz: Andalucía ayer y hoy. Ed. Planeta. Barcelona, 1983, pp. 142-144. Y de I. Moreno Navarro, «La identidad andaluza pasado y presente (una aproximación antropológica)». En Andalucia. Ed. Andaluzas Unidas, Sevilla, 1986, pp. 253-284. 
todas sus variedades y razas; es el estudio de sus facultades morales y psicológicas para poderlo apreciar en sus relaciones sociales y progresivas; en una palabra, la antropología nos da a conocer la historia física, social y filosófica de nuestra especie» ${ }^{15}$.

Tales concepciones nos situan en el contexto apropiado en el que nació esta nueva ciencia en el siglo XIX, entendida como uno de los auxiliares necesarios con que aportar pruebas irrefutables para la demostración del origen y el desarrollo del hombre. De ahí que este tipo de instituciones prosperaran por aquéllos entonces en Europa, nutriéndose fundamentalmente de médicos, naturalistas, arqueólogos y prehistoriadores. Animados, además, por el impacto definitivo de las teorías evolucionistas, y apoyados en la multitud de pruebas obtenidas por los viajes y exploraciones científicas alrededor del mundo, en una necesidad casi obsesiva, de recoger datos sobre «los salvajes contemporáneos». En la medida que la observación de sus formas de vida servían para la reconstrucción de estadios similares de la historia de la humanidad.

La Sociedad Antropológica de Sevilla se sumará así al ambiente científico predominante, el mismo que va a poner pronto a esta nueva ciencia de moda. Lo hacía, además, de forma casi pionera, pues sólo contaba con los ilustres precedentes, muy cercanos en el tiempo, de la Sociedad Antropológica de París y la Sociedad Antropológica de Londres, y desde luego, con la Sociedad Antropológica Española fundada en 1865 por el médico González Velasco, figura esencial para la historia de nuestra disciplina en España. Serviría además de relevo a esta última que, agobiada por las críticas de los sectores más integristas y falta de apoyo económico, viviría durante el sexenio revolucionario un estancamiento del que se recuperaría definitivamente tras los días de la Restauración ${ }^{16}$.

La sociedad sevillana, siguiendo el modelo de las ya existentes, se dividiría en tres secciones: Antropología Física, Antropología Psíquica y Antropología Social. Era el resultado de la concepción amplia de una ciencia que nacía sin prefijar claramente sus límites disciplinares. A cada una de las tres secciones quedaron adscritos estos intelectuales, distribuyéndose los darwinistas y natu-

15. A. Machado y Núñez: «Discurso inaugural de la Sociedad Antropológica de Sevilla». Revista Mensual, o.c. 1971, T. III, p. 355.

16. La Sociedad francesa fue inaugurada en 1859, contándose entre sus fundadores los prestigiosos nombres de Broca, Beclard, Isidoro Geoffroy y Saint Hilarie. A continuación sería inaugurada su homónima inglesa. Ver a propósito de P. Broca: «Prefacio» a la obra de Topinard: $L$ 'Antropologie. C. Reinwald Cie. Ed., París, 1877, pp. XII-XIII. La Sociedad Antropológica Española ha sido objeto de sendos estudios por: C. Lisón Tolosana: Antropología social en España. Siglo XXI. Madrid, 1971, pp. 97-159, y A.M. Verde Casanova; «La Primera Sociedad Antropológica de España». En Actas 1 Congreso Español de Antropología. Universidad Barcelona, 1980, vol. II, pp. 17-38. 
ralistas fundamentalmente en la primera, y repartiéndose entre las dos siguientes, los krausistas y algunos hegelianos, especialistas en su mayoría en Derecho, Historia, Filosofía y Literatura. Federico de Castro ostentaba la presidencia de la Sección Social, y con él uno de sus más importantes discípulos y colaboradores: Antonio Machado y Alvarez, además hijo único del ilustre catedrático de Historia Natural.

El joven Machado creció así rodeado de un privilegiado ambiente intelectual, pues su formación estuvo ligada a dos figuras cumbres de aquel período, las gestoras de todo este movimiento en Andalucía, y ligado igualmente a las dos corrientes de pensamiento vanguardista en esos momentos. Esto, junto a la influencia literaria de su tío, Agustín Durán, terminará por conformar una personalidad de una riqueza y altura de la que daría buena nota a lo largo de toda su trayectoria profesional.

\section{DE LA LITERATURA A LA INVESTIGACION CIENTIFICA}

Antonio Machado y Alvarez heredaría de su padre el espíritu y la curiosidad científica, así como un interés investigador centrado preferentemente en el marco andaluz. Al mismo tiempo que, en sus años de estudio en la Facultad de Derecho y en la de Filosofía y Letras con su maestro Castro, se imbuiría de los principios de un reformismo social basado en la interpretación armónica de la evolución de la humanidad, característicos del krausismo, como también lo eran su amor por la Historia y la Literatura propias, como forma de acceder y rescatar el verdadero espíritu nacional. Machado era un digno ejemplo, a la vez que un importante resultado de la confluencia de dos teorías, que por materialista la una, y por idealista la otra tuvieron problemas de coexistencia en otros lugares del país, y que sin embargo en Andalucía convivieron y colaboraron, anteponiendo a otras contradicciones de fondo el afán reformista e innovador que las dos preconizaban. Esta conjunción será la causa de la riqueza intelectual y de la complejidad de todo este período en Andalucía, así como de la singularidad de todas las realizaciones de este grupo.

Los primeros pasos los daría Machado y Alvarez dentro de la más pura ortodoxia krausista, a esta etapa responden sus serie de trabajos en la Revista Mensual, titulados genéricamente: «Apuntes para un Artículo Literario», en los que nuestro joven investigador, alentado por Federico de Castro, y ayudado de colaboradores como Alvarez Surga, se dedicaría a profundizar en las raíces de las producciones populares, dedicándose durante varios años, con verdadero entusiasmo, a recoger fielmente de boca del pueblo sus creaciones literarias. Era el gusto por la Literatura Popular, con mayúscula, lo que le 
impulsaba en esta tarea, empeñado, como estaba, en reconstruir la verdadera historia nacional, que se manifestaba sólo a través de sus obras estéticas, manipulada por la artificiosidad y el refinamiento de una literatura erudita y una cultura elitista. Se trataba de ir a las fuentes mismas de la creación espontánea, viva y fresca del pueblo, allí donde se encontraba el verdadero "genio nacional».

El concepto idealista de pueblo, tomado directamente de la filosofía alemana, latía claramente en estos pensamientos, relacionados también con toda una moda romántica que por entonces recorría Europa, y que no por casualidad había tenido también sus orígenes en Alemania. De cualquier forma, el pensamiento y la profundidad más trascendental de la filosofía de Krause estará más presente en toda esta etapa de Machado, que la influencia de un romanticismo que, al menos en nuestro país, careció de la complejidad intelectual que en otros lugares europeos. El afán científico por profundizar en los rasgos psíquicos del pueblo, más que el puramente estético, cuando no moralista y hasta lleno de tipismo, será lo que distinguirá, desde el principio, a Machado de sus ilustres predecesores románticos en Andalucía de Fernán Caballero, por citar uno de los más destacados ejemplos. De ahí estas rotundas aclaraciones con las que nuestro autor encabeza unos de sus primeros artículos:

«¿Queréis conocer la historia de un pueblo? Ved sus romances. ¿Aspiráis a saber de lo que es capaz? Estudiad sus cantares» ${ }^{17}$.

Quedan en esta etapa dibujados algunos de los temas claves sobre los que se desarrollará su trabajo posterior. El trabajo de recolección directa de las composiciones populares le pondría en contacto con algunos aspectos de la cultura popular andaluza, a la vez que lo harían poseedor de un rico arsenal de materiales sobre los que construiría todas sus posteriores teorías. El propio tema de la pronunciación andaluza constatada en las canciones populares le lleva ya a esbozar unas rápidas observaciones sobre un aspecto que para él respondía más a unas bases culturales, que a un uso erróneo del lenguaje:

«Así observamos que el andaluz muestra predilección por unas consonantes y aversión decidida hacia otras: gusta mucho de la aspiración de la $h$, y de la pronunciación de la $s$ como silbante, le fastidia y enoja: transforma en $r$ la $l$ por antipatía a su espíritu, y apenas si emplea la $d$ cuando no puede echarla a hombros ajenos. Este amor y este odio

17. A. Machado y Alvarez: «Apuntes para un Artículo Literario» en Revista Mensual, o.c. 1869, n. ${ }^{\circ} 1$, p. 175 . 
hacia las inofensivas letras, revela algo fundamental que no depende ya de la conformación del órgano físico, sino que sirve para descubrir a ese individuo mayor, sin nombre todavía, que marca el tránsito de la provincia (hoy imperfectisima división geográfico-política) a la nación o pueblo, individuo real, personal y vivo que tiene límite cierto, esfera propia y derecho suyo» ${ }^{18}$.

Por debajo del incuestionable sello krausista de tales argumentaciones, que en su consideración del pueblo como ser vivo lo llevan a describir tales pronunciaciones como acciones subjetivas del mismo, no podríamos encontrar una más detallada relación de algunas de las características del habla andaluza. Algo que no ha sido estudiado profundamente sino hasta época muy reciente. Y lo que es más importante, su señalamiento como uno de los marcadores de identidad de Andalucía, cuya existencia territorial y cultural, como conjunto diferencial respecto al resto se señala claramente, aunque sin terminar de formular todavía un nombre para una entidad, que respondiendo a la concepción de federalismo orgánico de la nación, típica de los krausistas, se situaría como realidad intermedia entre la provincial y la nacional.

Tampoco pasa por alto Machado uno de los elementos de la cultura popular: su caracter contestatario frente a unas normas y valores impuestos por la cultura dominante. Este caracter, este tono de protesta que, por no poder expresarse directamente, se refugia en las letras de muchas de estas composiciones es analizado por nuestro autor con ejemplos al respecto:

«A la puerta del presidio

Hay escrito con carbón

Aquí el bueno se hace malo,

El malo se hace peor».

«Cuando se emborracha un pobre,

le llaman el borrachón

cuando se emborracha un rico

qué alegrito va el señor» ${ }^{19}$

Por idéntico contenido y por ser uno de los puntales definidores de la cultura popular andaluza, tampoco podía dejar de fijarse Machado en los «cantes

18. Ibidem. p. 38 .

19. Ibidem. pp. 294-298. Sobre el carácter impugnador de las creaciones populares y en general de la cultura popular recomendamos la visión dada por L. Lombardi Satriani: Antropología Cultural. Análisis de la cultura subalterna. Ed. Galerna. Buenos Aires, 1975. Del mismo autor, Apropiación y destrucción de la cultura de las clases subalternas. Ed. Nueva Imagen, México D.F. 1978. 
flamencos», y lo hace, de nuevo adelantándose a su tiempo, para resaltar, no su tipismo, sino su especificidad y para detenerse en el controvertido tema de sus orígenes y de su complejidad:

«Nacidos muchas veces en la taberna y en ella casi siempre, por plazas y campos repetidos, son los cantes flamencos, como en otro artículo indicábamos, una mezcla de elementos heterogéneos, aunque afines; un resultado del contacto en que vive la clase baja del pueblo andaluz con el misterioso y desconocido pueblo gitano. Ellos indican ser hijos de una fantasía poderosa, si las hay, pero lúgubre y tétrica, no risueña y rica como la andaluza; presentan como carácter predominante la determinación pleonástica de los objetos, y una cierta pretensión de penetrar en la naturaleza íntima de las cosas...» ${ }^{20}$.

En 1871 la sección «Apuntes para un artículo literario» cesa su colaboración en las páginas de la Revista Mensual. Esta, a su vez, falta de apoyo cesa su publicación en 1874, tras seis años de continuado esfuerzo por situar la ciencia y el pensamiento intelectual español a la altura de los nuevos tiempos. Nacida como necesidad de dar respuestas a las inquietudes de la intelectualidad progresista, cuando las circunstancias políticas del país lo permitieron, parece lógico que acabara cuando esas mismas condiciones estructurales desaparecieron con la llegada de la Restauración. Toda una época se cerraba con su último número.

De momento la represión y el control ideológico volvía a las aulas universitarias, a la vez que directrices de conservadurismo tendían a encorsetar de nuevo la ciencia en este país. De cualquier forma, los cambios anteriores habían producido toda una generación de jóvenes científicos poco dispuestos a dar marcha atrás en sus conquistas. Por otro lado, el fracaso de la Revolución había desencantado a muchos progresistas, desencanto extensible a una de las ideologías que la habían sostenido: el krausismo. De ahí que durante todos estos años se produzca un paulatino desplazamiento de estos intelectuales desde las posturas idealistas a posiciones muchos más prácticas, más hacia un empirismo característico de la corriente positivista. El triunfo de éste era ya un hecho, al que había contribuido la continua aportación de nuevas pruebas sobre la evolución de la humanidad, la proliferación de nuevos campos científi$\cos$, la fundación por doquier de instituciones, sociedades científicas y museos sobre estas materias, así como la traducción y la difusión de las obras de Darwin y de otros evolucionistas y científicos.

20. A. Machado y Alvarez. Ibidem, n. ${ }^{\circ} 11$, p. 474. 
Este trasvase intelectual será paralelo al desarrollo definitivo de las Ciencias Sociales en España, que lógicamente necesitaban del concurso del método experimental. Y así abandonando cualquier otra orientación metafísica, se perfilaron los primeros estudios sobre materias como la Antropología Social o la misma Sociología. En la medida que, con esa formulación ecléctica resultante de ambas corrientes, llamada por muchos krausopositivismo, se aunó la vocación por los estudios sociales de la una, con la necesidad de la comprobación empírica de la otra. Este fue el recorrido personal que van a realizar hombres como Antonio Machado y Alvarez y Sales y Ferré, a los que les debemos, respectivamente, el inicio en nuestro país de la investigación en las mencionadas disciplinas.

Manuel Sales y Ferré, natural de Uldecoa (Tarragona) había venido a reforzar al grupo sevillano en esta nueva etapa ${ }^{21}$. Formado también en los núcleos krausistas de la universidad de Madrid, tomaría posesión de su cátedra de Geografía Histórica en la Universidad Hispalense y se incorporaría de lleno a las nuevas actividades de estos intelectuales andaluces, quienes superados los primeros impases de la Restauración se aprestaron a la creación de nuevos centros culturales y científicos, tal fue el caso del Ateneo Hispalense en 1878, la edición de la Biblioteca Científico-Literaria, concebida como una colección de libros para la difusión de las más importantes obras del pensamiento europeo del momento, y por último la Revista Científico-Literaria La Enciclopedia, de anterior existencia y a la que el grupo reorientará en contenido a partir de 1879. Su papel fue el de ocupar el puesto de la desaparecida Revista Mensual, aunque sus directrices responderán lógicamente a la evolución ideológica que en general había ocurrido en el grupo en esta segunda etapa.

Esta segunda opción, más clara en algunos del grupo que en otros, acarreará no serias controversias a estos intelectuales, y en este sentido merecen ser destacadas, por su trascendencia notoria, la famosa polémica mantenida en la prensa de la época por Manuel Sales y Ferré, tras su ciclo de conferencias en el Ateneo Hispalense titulado: «El hombre primitivo y las tradiciones orientales», donde el desplazamiento doctrinal del conferenciante hacia el positivismo quedó más claro que nunca, y donde se planteaban, a la luz de las nuevas teorías, los diversos mitos y creencias elaborados por las distintas religiones en torno al origen del hombre. Tales concepciones le ocasionarían una sonada disputa pública con la Revista Católica, portavoz de la postura oficial de la Iglesia y de los sectores más conservadores de la ciudad. No menos notoria sería la emprendida contra otro de los grandes conocedores del darwinismo

21. Sobre M. Sales y Ferré aconsejamos los trabajos de M. Nuñez Encabo: Manuel. Edicusa. Madrid, 1976; a cuyas pp. 17-25 remitimos para más datos biográficos. Asímismo la obra de R. Jerez Mir, «La introducción de la Sociología en España», M. Seles Ferré, Una experiencia truncada. Ed. Ayuso, Madrid, 1980, pp. 16-98. 
en Andalucía, el granadino Rafael García Alvarez, profesor del Instituto de Segunda Enseñanza de aquella ciudad, cuyo discurso pronunciado en la apertura del curso 1872-1873 le valdría la condena por herético por parte del Arzobispado granadino. García Alvarez, conocido y respetado en los círculos intelectuales progresistas del país sería otro de los grandes difusores de la teoría darwiniana, por demás, colaborador asiduo de otras de las publicaciones de notable altura científica de todo este período; nos referimos a la Revista de Andalucía, editada en Málaga desde $1974^{22}$.

Los cambios también fueron evidentes entre los estudiosos de las creaciones populares, quienes de nuevo encabezados por Antonio Machado y Alvarez firmaban la «Sección de Literatura Popular», dentro de La Enciclopedia. Cada vez más influidos por las investigaciones mitográficas desarrolladas por Max Müller, así como por la labor recopiladora y científica iniciada por los Hermanos Grimm en Alemania, el grupo se apresta a abandonar su orientación mayoritariamente esencialista y filosófica para adoptar criterios más empíricos, basados en la recogida sistemática de estos materiales, interesándose en una labor de clasificación y comparación, que les permitiera elaborar fundadas teorías sobre la génesis, evolución y difusión de los mismos:

«No son ya los cuentos y leyendas populares a los ojos de las gentes ilustradas asunto de puro entretenimiento y recreo para los niños y desahogo para las viejas; son unos verdaderos fósiles de civilizaciones primitivas y otras formas prehistóricas o históricas, algunas actuales, de pueblos salvajes; fósiles y monumentos que importa conocer, tanto por lo menos como los retos petrificados de especies de animales extinguidas; fósiles literarios los unos y monumentos prehistóricos los otros, que utilizan hoy los más ilustres europeos. Como ejemplo citaremos solamente dos, uno de los hermanos Grimm, y una saga (cuento) escandinavo que sirve al eminente Tylor en su obra La Civilización Primitiva, a que tanto debe el ilustre filósofo inglés Herbert Spencer» ${ }^{23}$.

22. El contenido de tales conferencias aparecerían posteriormente publicado a nombre de M. Sales y Ferré, El hombre primitivo y las tradiciones orientales. La ciencia y la religión. Impr. del Mercantil Sevillano. Sevilla, 1881. La polémica y las continuas contestaciones de la conferencia por parte de la Revista Católica aparecerían en dicha publicación bajo el título genérico de: «El hombre primitivo y los discursos del Sr. Sales y Ferré», en Revista Católica. Semanario de Ciencias Eclesiásticas y Literatura religiosa. Impr. Antonio Izquierdo y Sobrino. Sevilla, 1881, n. ${ }^{\circ}$ IV. Datos sobre la controversia suscitada en torno a R. García Alvarez en T. Glick, o.c. 1982 , pp. $47-48$.

23. A. Machado y Alvarez: «Sección de Literatura Popular», La Enciclopedia. Impr. Carlos M. Santigosa. Sevilla, 1879, T. III, p. 22 . Se refería Tylor en esta obra publicada en 1874 , a la creencia de algunos pueblos de Nueva Zelanda de que el alma abandona el cuerpo durante la noche, en viaje de ida y vuelta. 
Afirmación que se completaba explicítamente con la idea de que ninguna creación popular podían, ser motivo de la curiosidad de los estudiosos por su rareza, su ingenio o la singularidad de su composición, antes bien, cualquier material de este tipo: coplas, adagios, adivinanzas, trovos, leyendas y demás, sólo podían ser estudiados como «materia científica». Quedaban así ya claramente diseñado, la dirección y la corriente metodológica en la que, a partir de ahora, se van a insertar este tipo de investigaciones en clara conexión con toda la escuela evolucionista. Por ello, y por su mismo objeto de trabajo, adscribiéndose ya a una campo muy cercano al de la propia Antropología. Es en ese sentido, por lo que Machado termina este artículo señalando algunas de las teorías al respecto de uno de los primeros antropólogos, el inglés Tylor.

Los años al frente de la esta Sección en La Enciclopedia fueron decisivos para el grupo, al que se habían incorporado algunas figuras como el escritor Francisco Rodríguez Marín, literato y escritor natural de Utrera, y a partir de entonces, compañero y colaborador insustituible de Antonio Machado y Alvarez. Ambos recogerían ingente cantidad de materiales de todas las provincias andaluzas que, por la calidad de sus publicaciones, les puso en contacto con otros estudiosos del campo a nivel nacional e internacional. El intercambio de ideas y materiales les permitiría ampliar, perfilar y enriquecer sus concepciones originales, a la vez que los situaba de lleno dentro de todo este movimiento europeo de definición e interés por lo popular de finales del XIX. Las colaboraciones a partir de entonces con figuras como las del italiano Pitré, el francés Gastón París, y los portugueses Braga y Coelho fueron asiduas; de la misma forma que lo eran con otros intelectuales españoles, entre quienes destacaba la personalidad del catalán Milá y Fontanals. Epoca especialmente fructífera, en la que además Antonio Machado y Alvarez prepararía la edición de su libro: Colección de Cantes Flamencos (1881), que aparecería firmado ya por «Demófilo», sobrenombre que desde entonces adoptaría. Culminaba con esta obra una trayectoria iniciada años atrás, en los días de la Revista Mensual. Ese mismo año, Rodríguez Marín iniciaba la publicación del primer tomo de la que fue su más interesante obra: Los Cantos Populares Españoles ${ }^{24}$.

\section{LA CONCEPCION DE FOLKLORE}

El campo, a nivel teórico y metodológico, estaba suficientemente abonado cuando a este grupo les llegó la noticia de la concepción de una nueva materia científica nacida y bautizada en Inglaterra: el Folk-Lore, o lo que era lo mis-

24. Nos referimos a las respectivas obras de Demófilo: Colección de cantes flamencos, recogidos y anotados por... Impr. El Porvenir, 1881. F. Rodríguez Marín, Cantos Populares Españoles. Francisco Alvarz y Cía. Ed. 1862-1883. 
mo: el estudio del «Saber Popular» tal y como se traducía literalmente esta palabra compuesta. Término acuñado por Sir Williams Thoms en 1848 para dar nombre a una disciplina que comenzaba por entonces a perfilarse, pero que no sería utilizado hasta 1879 para denominar la primera institución de este tipo que surgía en el mundo la: Folk-Lore Society, fundada en Londres por un grupo de mitógrafos, literatos y otros estudiosos del mundo de lo popular.

Se trataba de dar un paso más amplio y, desde la Literatura oral, abrir un marco de interés más extenso que englobara también las demás creaciones culturales del pueblo puestas en relación e interpretadas en su propio contexto cultural, considerándolas expresión y manifestación del mismo. Este importante matiz diferenciaba y definía la orientación del Folk-Lore de los estudios meramentes literarios, que atendían más a la estructura externa de tales creaciones, sin profundizar en el universo de valores del pueblo que las producía. Se insertaban, de otro lado, estos nuevos estudios, en la dirección de avance de las todavía jóvenes disciplinas de las ciencias sociales que, con inequívocas orientación evolucionistas, pretendían aportar datos al conocimiento del desarrollo de la humanidad.

Las analogías que se establecieron entre el grado de evolución de las capas sociales más atrasadas y las civilizaciones precedentes, sirvieron para aplicar el concepto de «supervivencias», creado por Tylor en el campo de la Antropología. Se trataba, mediante el uso del método comparativo, de intentar reconstruir las fases de la historia de la humanidad, a través de los elementos rezagados de etapas anteriores que aún sobrevivían en las capas populares actuales, por definición, menos evolucionadas. El Folklore ponía sus ojos en el «pueblo», identificados, por lo general, con los campesinos y otros grupos tradicionales de ámbito rural, mientras que la Antropología los dirigía hacía los «salvajes». En uno y otro caso, se trataba en esencia de estudiar a «los otros», internos o externos, en la base a considerarlos testigos vivientes de etapas anteriores, por las que también había pasado la civilización «occidental», o las capas ilustradas y superiores de la misma. Era, de esta forma, una conceptualización que partía de una valoración previa y científica de oposición, en términos de superioridad-inferioridad.

Pronto contaría Machado y Alvarez con un ejemplar de los Estatutos de la Sociedad inglesa, enviados, ante sus requerimientos, por su secretario Mr. Gomme. Basándose en ellos y con la prontitud de acción se caracterizaba a nuestro grupo, para 1881 la creación de Sociedad de Folk-Lore Español era un hecho y con ella comenzaba la aventura definitiva de unos investigadores que, desde entonces, hay que situarlos entre los iniciadores del movimiento folklorista europeo del XIX, y de una nueva disciplina: El Folklore, cuyas bases tendieron a fijar con sus trabajos concretos y con sus reflexiones teóricas. Así quedaba expresado en sus Estatutos: 
«Esta Sociedad tiene por objeto recoger, acopiar y publicar todos los conocimientos de nuestro pueblo en los diversos ramos de la ciencia los proverbios, cantares, adivinanzas, cuentos, leyendas, fábulas, tradiciones y demás fórmulas poéticas y literarias; los usos, costumbres, ceremonias, espectáculos y fiestas familiares, locales y nacionales; los ritos, creencias, supersticiones, mitos y juegos infantiles en que se conservan más principalmente los vestigios de las civilizaciones pasadas; las locuciones, giros trabalenguas, frases hechas, motes y apodos, modismos, provincialismos y voces infantiles... y en suma, todos los elementos constitutivos del genio, del saber y del idioma patrio, contenidos en la tradición oral y en los monumentos escritos, como materiales indispensables para el conocimiento y la reconstrucción científica de la historia y de la cultura española» ${ }^{25}$.

Varias particularidades separaron desde siempre a este grupo de sus homónimos europeos. Primero, fue la misma concepción descentralizada de la Sociedad, creada en forma federal, constituida por ello, «por tantos centros cuantas son las regiones que constituyen la nacionalidad española» ${ }^{26}$. Suponía esta premisa el reconocimiento taxativo de la existencia de una pluralidad de la cultura en el Estado Español. Y era precisamente la misión fundamental de la Sociedad, la de descubrir e identificar los rasgos y peculiaridades de cada una de estas entidades culturales.

La otra diferencia, sobre todo con los folkoristas ingleses, está íntimamente ligada a la anterior, y consistió en su concepción menos arqueologista del Folklore y mucho más contemporánea. Es decir, y sin que ello supusiera dejar de aceptar la teoría de las supervivencias, se trabajó menos de cara a descubrir las formas de vida del hombre prehistórico, y más a desentrañar las características culturales de cada pueblo contemporáneo en concreto. Esta orientación desarrollada en algunas de sus discusiones científicas, atendía más a las producciones modernas y ponía en entredicho la simplicidad y el excesivo mecanicismo con que se solían hacer las analogías entre las formas de vida pasadas y presentes. En este sentido, sus concepciones guardaron más conexión con el campo actual de la Antropología que las de otros folkloristas. Aunque evidentemente, con estos compartieron su atención preferente por producciones generalmente orales, y de componente sólo ideológico.

Lógicamente, sería la Sociedad del Folk-Lore Andaluz, la primera en constituirse, lo haría casi al mismo tiempo que la institución estatal. Y por lógica

25. «Bases de El Folk-Lore Español. Sociedad para la recopilación y estudio del saber y de las tradiciones populares». En: El Folk-Lore Andaluz. Tres-Catorce-Diecisiete. Madrid, 1981. Apéndices.

26. Ibidem. Artículo $2 .^{\circ}$. 
también, sobre ella recaería todo el esfuerzo propagandístico y de contacto con personalidades y estudiosos de otros lugares, con vistas a gestionar la formación de cada centro. A partir de ese momento la actividad fue febril, y para ello la colaboración de la prensa fue, a todos los niveles, esencial. De ahí la multitud de artículos de información o de seguimiento de los trabajos realizados que los andaluces enviaron a periódicos de distinta cobertura nacional. Dirigiendo todo el grupo, con sede en Sevilla, estaba Antonio Machado y Alvarez, antiguos colaboradores, tales como Rodríguez Marín, y nuevas figuras que terminarían de configurar el grupo de los folkloristas andaluces. Entre ellos destacaremos a Alejandro Guichot y Sierra, profesor de Dibujo y gran especialista en los temas de Mitología, hijo de Joaquín Guichot y Parody, autor entre otras de la primera Historia General de Andalucía, escrita en la temprana fecha de 1869. Con el tiempo Alejandro Guichot llegaría a convertirse en el organizador y propagador por excelencia del movimiento, en el apoyo insustituible de Machado, y en el posterior biógrafo de todo este período ${ }^{27}$. Junto a él Luis Montoto y Rautenstrauch, el literato costumbrista del grupo.

Desde marzo de 1882 a febrero de 1883 se editaría la revista El Folk-Lore Andaluz que, con una asiduidad mensual, llegaría a publicar un total de doce números. Fue el órgano de la Sociedad andaluza, y la más importante publicación de su género en nuestro país, en esos momentos, lo que le valdría el reconocimiento de los investigadores y las restantes publicaciones europeas de Folklore. Constituye, por la calidad y variedad de sus trabajos teóricos y sobre todo de recolección, uno de los más interesantes archivos sobre la cultura popular andaluza, y por lo tanto un material de indudable valor para su estudio. Coutarían los folkloristas con la colaboración puntual en esta tarea de los siempre compañeros de trabajo: Federico de Castro, Antonio Machado y Núñez, Manuel Sales y Ferré, así como la de conocidos intelectuales a escala nacional e internacional, en cuyas respectivas revistas también publicarían nuestros folkloristas.

A pesar de todo el esfuerzo, el centro andaluz no llegaría a consolidarse y sólo se lograría la creación de un sólo centro provincial: la Sociedad del FolkLore Gaditano, en 1885, que contaría durante el año de su existencia con su propio órgano El Boletín Folk-Lórico Gaditano. Algún otro centro local completaría la escasa nómina del proyecto andaluz. La misma tónica sucedería en el resto del Estado. De entre todos merece destacarse por su temprana formación, 1882, por su estrecha colaboración desde siempre con el grupo andaluz y por la importancia de sus realizaciones, la Sociedad del Folk-Lore Frexnense,

27. Sobre A. Guichot y Sierra es de obligada consulta la obra de J.R. Jiménez Benítez: La sociología andalucista de Alejandro Guichot. Fundación Blas Infante. Sevilla, 1990. Todo este motivimiento de folkloristas quedaría recogido en la obra de Guichot: Noticias Histórica del FolkLore. Hijos de Guillermo Alvarez. Sevilla, 1922. 
que lograría una presencia más que notable en todos los pueblos de la comarca. Encabezado por la singular figura de Luis Romero y Espinosa, artífice igualmente de su revista: El Folk-Lore Frexnense la única comparable, por su calidad, a la andaluza, con la que llegaría a fusionarse a partir de 1883 bajo la denominación El Folk-Lore Bético-Frexense. Con todo nunca se lograría la creación del centro extremeño. Si lo haría, en 1882, El Folk-Lore Asturiano; en 1883 le llegaría el turno al Folk-Lore Castellano, patrocinado por el propio Machado, tras el traslado de su residencia a Madrid; después vendrían la Sociedad del Folk-Lore Gallego, en 1884, presidida por Emilia Pardo Bazán; y por último, al año siguiente El Folk-Lore Vasco-Navarro.

Ningún otro centro llegaría a funcionar, y sólo con los catalanes se arbitraría una fórmula especial, la de la creación en 1885 dentro de la Asociación de Excursiones Catalana, de una sección llamada "El Folk-Lore Catalán». Sería el único contacto a nivel institucional del proyecto catalán y el preconizado por los andaluces. Realmente, la historia de los estudios de la literatura y de las tradiciones populares tuvo una dinámica propia y específica en Cataluña, remontable a los días de la Reinaxença. La peculiaridad y personalidad de este movimiento, influido por el romanticismo, pero más en conexión con una burguesía de tendencia política federalista pi-margaliano, no podía terminar de asumir un movimiento cuyo propio planteamiento federal todavía contemplaba los principios organicistas y esencialistas característico del krausismo, por tanto menos funcionales y ya obsoletos para las necesidades de la nueva burguesía industrial de fines del XIX ${ }^{28}$.

El sueño de la Sociedad del Folk-Lore Español quedaría sólo en un proyecto frustrado, que aglutinaría voluntades colectivas y trabajos de investigación interesante durante su período de gestación. Ahí quedan además de los correspondientes a cada centro, las interesantes obras colectivas: El Boletín FolkLórico Español (1885), dirigido por Guichot y Sierra, y la gran colección en once volúmenes: La Biblioteca de las Tradiciones Populares, codirigidas por Machado y Alvarez y Guichot, que durante los años 1884-1886 reuniría en sus sucesivos números una muy representativa muestra de la labor de los folkloristas españoles. La obra constituye, asímismo una de las principales aportaciones a la historia del folklore europeo ${ }^{29}$.

28. Sobre el movimiento folklorista en Cataluña remitimos al interesante trabajo de Llorenç Prats i Canals: El mite de la tradició popular. Els origens de l'interes per la Cultura Tradicional a la Catalunya del segle XIX. Edicions 62. Barcelona, 1988. Así como a la obra colectiva de LL. Prats, D. Llopart y J. Prat: La cultura popular a Catalunya. Serveis de Cultura Popular. Barcelona, 1982.

29. Biblioteca de las Tradiciones Populares. Dirigida por A. Machado y Alvarez. 1884-1886. 11 volúmenes. T.I.: F. Alvarez y Cía. Ed. Sevilla, 1884. T. II-XI: Fernando Fé. Madrid, 18841886. 
Quedarían también las obras personales de las cabezas visibles del movimiento, las reflexiones teóricas de Machado sobre la copla popular, o sus continuas conceptualizaciones sobre temas como la religiosidad popular andaluza, las fiestas, sobre el carácter dinámico y creativo de la cultura popular y sus definiciones, sobre los objetivos y el campo del Folklore, tema en el que incluso participaría en la pública polémica provocada por los más destacados folkloristas ingleses. Igualmente destacables son sus escritos de contenidos metodológicos, sobre la fidelidad de la recolección y la aplicación de la novedosa técnica de la fotografía, sobre la rigurosidad de la confección de Cuestionarios, y de la clasificación de los datos. Guichot, por su lado, nos dejaría sus reflexiones en torno a la formación y evolución de los mitos, sobre las supersticiones populares, así como su personal valoración y juicio de todo este movimiento del que él mismo participaría. Las aportaciones de Rodríguez Marín con sus colecciones de canciones y refranes populares, merecen ser destacadas, junto a los trabajos sobre las costumbres populares andaluzas de Luis Montoto $^{30}$.

Ante tantos entusiasmos no correspondidos, cansado y falto de apoyo económico Machado y Alvarez abandona toda dedicación pública y continua al Folklore a partir de 1887, cuando hacía un año que la desaparición de los centros regionales era ya un hecho. A partir de entonces se volcará en las traducciones de algunas obras científicas y sobre todo, en la colaboración, como comentarista jurídico, con algunas publicaciones de la prensa madrileña. Por fin en 1892, abandona España, buscando la seguridad económica y el bienestar que aquí se le negó, embarcando rumbo a Puerto Rico, para hacerse cargo de un puesto de Registrador de la Propiedad. Su delicada salud, agravada por tantos años de febril trabajo, le haría regresar al poco tiempo, enfermo, para morir en Sevilla en 1893 a la edad de 46 años.

Con su desaparición se cierra una de las etapas más ricas a nivel intelectual y de realizaciones concretas existentes en Andalucía en los últimos tiempos. Un movimiento, de otro lado, que por su misma amplitud y complejidad tendría resultados desiguales. Y así, la figura de los folkloristas aquí señalados, y de Machado y Alvarez, por encima de todos, descuella, sobre la medianía de los restantes, porque, a la hora del balance, habría que señalar la falta de teoricidad de un grupo que, llevado por la necesidad urgente, a veces elevada a la categoría de obsesiva, de recolectar unos datos en trance de desaparición,

30. Sería muy extenso pormenorizar la amplia obra de cada uno de estos folkloristas. Por no haber sido mencionada anteriormente, merecen ser destacadas: A. Guichot y Sierra: Las supersticiones populares andaluzas comparadas con las portuguesas, en Biblioteca de las Tradiciones Populares, o.c. 1883; y Ciencia de la Mitología. El gran mito Chtónico-Solar. Ibidem., 1884. De L. Montoto y Rautenstrauch: Las costumbres populares andaluzas. Ibidem., 1883-1884. Рara más datos remitimos a E. Aguilar Criado, o.c. 
no reparó en abrirse al concurso de cuantos voluntarios estaban dispuestos a colaborar en la tarea, personas de buenas intenciones, pero de dudosa preparación en su mayoría, que confundiendo ciencia con amateurismo y eruditismo, elaboraron trabajos de dudosa calidad, cuando no meras relaciones de creaciones populares, a veces rayando en el costumbrismo.

Parece evidente que todas las deficiencias conceptuales del movimiento tienen que ser revisadas a la luz de nuestras visiones actuales, pero, desde luego, explicadas dentro del contexto histórico en el que fueron elaboradas. Este es el caso de los conceptos elaborados en torno a «cultura popular» y «pueblo», asociándolos a una sola capa social: la obrera, campesina o urbana sin señalar, además, explícitamente sus límites socioeconómicos, atribuyéndoles, por extensión todos los valores sustanciales de una pretendida identidad nacional que explicaría las características culturales de las clases y capas sociales. Se definía así el todo por lo que sólo era una parte del mismo.

El fracaso del movimiento no se debió únicamente a estos fallos internos, entre los que se movió este nuevo campo científico, y que por tanto fue común a otros folkloristas de dentro y fuera de nuestro país. En su caso concreto el motivo fue la falta de apoyo en la que se movieron sus investigaciones, que hizo vano tantos sacrificios personales, y esfuerzos, muy superiores en general a sus posibilidades reales, sobre todo en lo que supuso el intento por introducir, difundir y extender estos estudios a otros lugares del Estado Español. El desprecio e incluso las ridiculizaciones de la intelectualidad más integrista, y el desentendimiento por parte de una burguesía tan peculiar en esos momentos, como la andaluza, hizo todo lo demás.

Desde luego, mucho tendría que ver la peculiaridad de la burguesía agrícola andaluza en el fracaso de este movimiento. No olvidemos que es una clase social que, tras el pacto canovista, está más pendiente de su ascensión política a cargos concretos en Madrid, que al propio desarrollo económico de Andalucía, donde la creciente y reciente actividad y radicalización del movimiento obrero campesino y urbana les había hecho temer por la integridad de sus negocios. Era pues más operativo desmantelar la ascendente industrialización andaluza y potenciar y apostar por el desarrollo de otras zonas del país. Son estos momentos cruciales en los que se perfila lo que iba a ser el futuro mapa de los centros y las periferias económicas de Estado Español. Bien poco interesada podía estar esta burguesía por valoracion alguna sobre la cultura andaluza que no fuera la de señalar la necesidad de su dependencia, anulando cualquier intento por destacar su especificidad con respecto a las restantes. Y, desde luego, con no muy buenos ojos podían ver el protagonismo que los folkloristas concedían a las clases más desfavorecidas, así como el descubrimiento del carácter contestatario, que a veces, y a nivel simbólico, este tipo de creaciones populares tenían, reflejando en sus letras algunas de las profundas contradicciones de la estructura socioeconómica andaluza. 
Su fracaso coyuntural no anula en absoluto la valía de su obra, importante a dos niveles: primero en cuanto a haber sido los iniciadores del Folklore en nuestro país, y, en segundo lugar, y por lo que a Andalucía se refiere, por ser los primeros definidores de sus bases culturales. En este sentido su labor supuso el primer descubrimiento de la etnicidad andaluza. Descubrimiento; desde luego, tan minoritario, como aislado, reducido a los pequeños círculos folkloristas, de ascendencia pequeño burguesa, que con el elitismo paternalista característico de este grupo social a fines del XIX, mal podía interesar a la propia clase obrera, la protagonista de sus estudios, con cuyos movimientos y reivindicaciones jamás lograría conectar.

Más extraña es su falta de imbricación con su inmediato sucesor en el tiempo, el movimiento regionalista andaluz. Y eso que ambos se gestaron en los mismos círculos institucionales y se nutrieron de similares composición de sectores sociales. El mismo Alejandro Guichot, participaría en ambos. El olvido casi total de los folkloristas por parte de los ideólogos del grupo andalucista, encabezado por Blas Infante es, pues, digno de destacar: señalando que las bases ideológicas del andalucismo histórico, las buscaría su líder en una interpretación idealista de la historia y la cultura andaluza, visión muy alejada de las aproximaciones empíricas elaboradas sobre estos mismos temas por los folkloristas.

La falta de apoyo de sus contemporáneos dió paso al olvido de sus sucesores, y así, Antonio Machado y Alvarez, quedó asociado para muchos con el cuidador del sevillano palacio de las Dueñas, y ello gracias a las diversas alusiones al respecto de su hijo, el poeta Antonio Machado. Las demás figuras, y en general la complejidad intelectual de un movimiento que era mucho más rico conceptualmente quedaron silenciadas hasta en el muy citado y conocido libro de Cocchiara sobre La Historia del Folklore en Europa ${ }^{31}$, donde ni se los menciona, cuando si se hace lo propio con los restantes folkloristas europeos de la época, con los que mantuvieron un intenso contacto.

Han tenido que pasar algunos años, para que, desde la perspectiva de la actual Antropología, y en base a la revisión del término de cultura popular, el papel de estos folkloristas andaluces haya comenzado a ser analizado en una perspectiva histórica y en su significado actual. Desde esta doble visión, ha ser reivindicado su papel de pioneros en la tarea de introducir el estudio de la cultura popular en el campo científico, de construir todo un sistema teórico y un planteamiento metodológico para acercarse a estas producciones. Fueron, en este sentido, no sólo los introductores en España de la nueva disciplina del Folklore, sino los precursores de los actuales estudios de Antropología por lo que a Andalucía se refiere, en cuyo contexto se movieron, aleján-

31. G. Cocchiara: Storia del folklore in Europa. Edizione Scientifiche Eillandi. Torino, 1952. 
dose de los meros planteamientos literarios de muchos de sus coetáneos. Y ello porque su formación y la gestación de las bases teóricas de este grupo se dió en las mismas coordenadas y en planteamientos muy cercanos a los que se movió la Antropología en su nacimiento. No podía ser una casualidad que en este contexto precisamente Antonio Machado y Alvarez fuera el traductor en 1887 del primer manual de esta ciencia: Antropología. Introducción al estudio del hombre y la ciencia de E. Tylor. Como tampoco la sería el que en 1911, con indudable carácter enciclopédico, Alejandro Guichot escribiera su obra Antropo-Sociología. 